\title{
Development and validation of stability indicating LC-MS/MS Technique for the quantification of tapentadol in biological matrices: Application to bioavailability study in healthy rabbits
}

\author{
Phanindra Adluri*, Yamsani Shravan Kumar \\ Faculty of Pharmaceutical Sciences, Mewar University, Chittorgarh, India.
}

\section{ARTICLE INFO \\ Received on: 09/03/2019 \\ Accepted on: 20/08/2019 \\ Available online: 05/10/2019}

\section{Key words:}

Tapentadol, LC-MS/

MS, validation, matrix

effect, healthy rabbits and

bioavailability study.

\begin{abstract}
An Liquid chromatography tandem mass spectrometry (LC-MS/MS) technique is one of the best analytical methods for the quantification of drugs in biological samples. Astability-indicating analytical technique was developed for the quantitation of tapentadol in biological matrices as tapentadol with short runtime. Developed technique also suitable for bioavailability studies in healthy rabbits. Separation of tapentadol and tapentadol-d3 were achieved from plasma sample with solid-phase extraction and elution was processed with Luna- $\mathrm{C}_{18}(5 \mu, 100 \mathrm{~mm} \times 4.6 \mathrm{~mm})$ stationary column with movable phase ratio comprising 2-mM ammonium acetate buffer $(\mathrm{pH}-3.6)$ and acetonitrile in the proportion of 10:90\% V/V. Quantitation was processed by processing the transitions of tapentadol and tapentadol-d3 at $m / z 222.2 \rightarrow 177.1$ and $228.2 \rightarrow 183.1$, respectively, in positive ionization mode. Linearity was performed over the concentration range of 0.121 to $35.637 \mathrm{mg} / \mathrm{ml}$ $\left(R^{2}>0.99\right)$ without matrix effect $(2.74 \%)$. The inter- and intra-day precision findings were within $8.62 \%$ and $11.38 \%$, respectively. Stability data showed that the tapentadol was stable when it exposed to different stability conditions. This technique was effectively applied to bioavailability studies of tapentadol in healthy rabbits.
\end{abstract}

\section{INTRODUCTION}

Tapentadol (TPD) is a synthetic analgesic drug which acts centrally. Analgesic activity of drug is due to $\mu$-opioid agonist action and it prevents nor-epinephrine reuptake. Morphine is 18 times more potent than tapentadol to bind $\mu$-opioid receptors and tapentadol is less effective in animals to induce analgesia. TPD increases noradrenaline concentrations by obstructing the noradrenaline reuptake at brain of the tats (Fidman and Nogid, 2010; Mahaparale and Samuel, 2015; Singh et al., 2013). TPD produce its analgesic effect without an active metabolite. It is chemically designated as 3-[(1R, 2R)-3-(dimethyl amino)-1- ethyl-2-methyl propyl ] phenol hydrochloride.

An average absolute bioavailability is $32 \%$ approximately due to first-pass metabolism after single-dose administration.

*Corresponding Author

Phanindra Adluri, Research Scholar, Mewar University, Chittorgarh,

India.E-mail: mrphanipharma1981@gmail.com
Maximum TPD serum concentration was observed after 1.25 hours (after dosing). A multiple dose (every 6 hours) study with vary in dose from 75 to $175 \mathrm{mg}$ TPD showed an average of 1.6 accumulation factor to parent drug and 1.8 is for main metabolite (TPD-O-glucuronide), which were estimated primarily by medicating interval and half-life of TPD and drug metabolite (Leonhart, 2009; Raffa, 2012; Tzschentke et al., 2006; WHO, 2014).

In humans, TPD $\mathrm{HCl}$ metabolism is extensive, because $97 \%$ of parent drug is metabolized. Most of the drug is metabolized through Phase-2 path, and few amount metabolized through Phase-1 pathway (oxidative). The major metabolism pathway of TPD is glucuronic acid conjugation to yield glucuronide. After administration of drug by oral route, $70 \%$ (O-glucuronide $-55.0 \%$, sulfate of TPD-15\%) of the drug dose is eliminated as conjugated form in the urine (Nossaman et al., 2010; WHO, 2014).

Literature review unveils that one Liquid chromatography tandem mass spectrometry (LC-MS/MS) (Coulter et al., 2010) 
method and two High performance liquid chromatography (HPLC) methods (Gaurang and Hitendra, 2013; Mahaparale and Samuel, 2015) were described for the quantification of TPD. No reported technique was on bioavailability study on healthy rabbits. The goal of the research was to develop a fast and sensitive bioanalytical technique for the quantitation of TPD in plasma samples and application of pharmacokinetics in healthy rabbits by LC-MS/MS.

\section{MATERIALS AND METHODS}

\section{Chemicals and materials}

TPD (LS, purity: 99.7, Batch No.: T3A03,) and TPD-d (internal standard, Lot No.: CK-LT-365, purity: 98.85\%) were bought from the MSN Labs, India, (chemical structure shown in Fig. 1) Acetonitrile and ammonium acetate were obtained from SD-Fine Chemicals, India. Acetic acid was acquired from MJ chemicals, Mumbai, India. Millipore water from Moscheim Cedex system utilized in processing of standard and sample solutions. SPE-cartridges were gained from Agela Technologies, China. The animal studies on healthy rabbits were approved by institutional ethical committee no-1292/ac/09/CPCSEA/17-43/A.

\section{Liquid chromatography}

Chromatographic separation achieved on LC-Shimadzu scientific instrument with Luna-C18 $(5 \mu, 100 \mathrm{~mm} \times 4.6 \mathrm{~mm})$ stationary column. Mobile phase ratio comprising ammonium acetate buffer $(2 \mathrm{mM})$ and acetonitrile in the proportion of 10:90\% $\mathrm{V} / \mathrm{V}$ was processed at $0.7 \mathrm{ml} /$ minute flow rate. The chromatographic elution was completed in 4.5 minutes for each single analysis.

\section{Mass system conditions}

The mass detection was processed on mass system, MDS-Sciex atmospheric pressure chemical ionization (API)4000 (Canada), furnished with electro-spray ionization ran in +MRM mode. The component and system source constraints were finalized through injecting TPD and TPD-d3 individual solutions into mass system. The optimized component parameters to monitoring TPD and TPD-d3 were as follows: Ccollision cell exit-potential: $6 \mathrm{~V}$; entrance potential, $12 \mathrm{~V}$; declustering potential, $36 \mathrm{~V}$; and collision energy, $18 \mathrm{~V}$. Mass instrument source conditions were optimized as: turbo-ion spray voltage, 5,000 V; nebulizer gas, 55 psi; collision-activated dissociation gas, 5 psi; heater gas, 45 psi; curtain gas, 18 psi and source temperature, $400{ }^{\circ} \mathrm{C}$. Q1 and Q-3 were processed at unit resolution with dwell time of $200 \mathrm{~ms}$ for two analytes. Quantitation was processed by

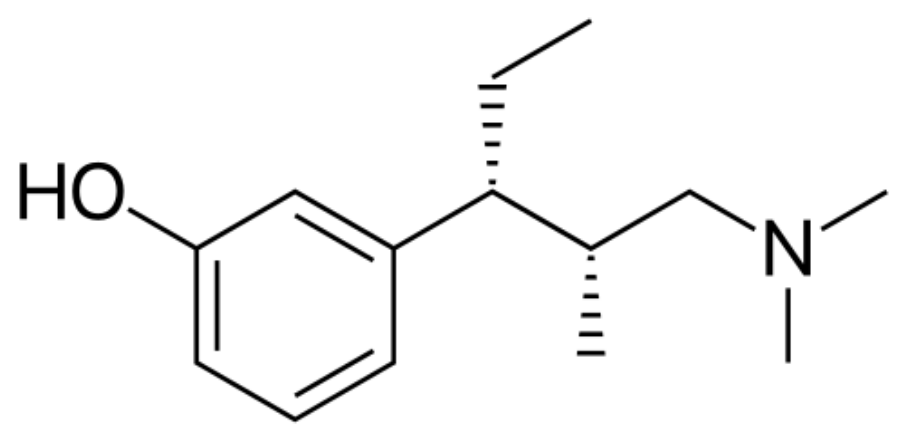

Figure 1. Structure of Tapentadol. monitoring the transitions of tapentadol and tapentadol-d3 at $\mathrm{m} / \mathrm{z}$ $222.2 \rightarrow 177.1$ and $228.2 \rightarrow 183.1$, respectively, in the positive ionization mode. Analyst software version 1.4.2 utilized for data acquisition and integration (MDS-Sciex, Canada) (Chen and Hsu, 2013; Jaivik et al., 2017; Patel et al., 2017).

Protocol for stock, quality control, and calibration standard solutions

Two separate TPD-stock solutions were processed for CS (calibration standard solutions) and QC (quality control solutions) samples for the method validation and sample analysis. TPD and TPD-d 3 stock solutions were processed with acetonitrile to get $1 \mathrm{mg} / \mathrm{ml}$ concentration. CS and QC working solutions were processed through suitable dilution with $50 \% \mathrm{~V} / \mathrm{V}$ acetonitrile in water. Blank plasma ( $\mathrm{K}_{3}$ EDTA) was infused into system before spiking to confirm that no matrix components interference at the retaining time of TPD and TPD-d3. An eight-point CS and QC-samples at four different concentrations were processed by spiking blank plasma with required quantity of TPD. CS solutions were prepared at concentration level of $0.1210,0.3280,1.6420$, $4.1050,10.2640,17.1060,28.5100$, and $35.6370 \mathrm{ng} / \mathrm{ml}$ and quality control solutions at Lower limit of quantification quality control (LOQQC), Lower quality control (LQC), Medium quality control (MQC), and High quality control (HQC) at concentration level of $0.1220,0.3590,14.3580$, and $28.7160 \mathrm{ng} / \mathrm{ml}$, respectively (Badenhorst et al., 2000; Haritos and Ghabrial, 1999). The TPD-d3 working solution $(150.0 \mathrm{ng} / \mathrm{ml})$ was processed from TPD-d3-stock solution with $50 \% \mathrm{~V} / \mathrm{V}$ acetonitrile in water.

\section{Protocol for sample preparation}

$300 \mu \mathrm{l}$ Plasma sample and $50 \mu \mathrm{l}$ of TPD-d3 working solution $(150 \mathrm{ng} / \mathrm{ml})$ were transferred in ice-cold water bath and mixed well. To the resulting solution, buffer of $100 \mathrm{mM}$ ammonium acetate $(500 \mu \mathrm{l})$ was transferred and vortexed. The resulting samples were transferred into the pre-conditioned cartridge (CleanertPEP-3) and centrifuge (at 50,000 rpm) for 2 minutes at 2 to $10^{\circ} \mathrm{C}$. The cartridges washed with $20 \%$ methanol $(1 \mathrm{ml})$, and components were separated with $1 \mathrm{ml}$ of acetonitrile. Then, extracted samples evaporated (at $40^{\circ} \mathrm{C}$ ) to dryness under dry nitrogen stream utilizing Zymark Turbo-Vap-LV evaporator. Dried component was processed with $300 \mu \mathrm{l}$ buffer of $5 \mathrm{mM}$ ammonium acetate (pH-3.6) and acetonitrile in the proportion of $40: 60 \% \mathrm{~V} / \mathrm{V} .20 \mu \mathrm{l}$ of resulting solution was infused into chromatographic system.

\section{Method validation}

The developed TPD-method was validated as per the guidelines of United States Food and Drug Administration (USFDA) and European Medicines Agency (EMEA) in human plasma. The technique was validated for specificity, precision, linearity, sensitivity, process efficiency, accuracy, re-injection reproducibility, matrix effect, dilution integrity, and stability study of TPD.

\section{Selectivity and sensitivity}

Selectivity of the method toward matrix metabolites, constituents, and associated medicaments were evaluated by screening 10 batches (2-lipemic, 2-haemolyzed, and 6-normal) of human plasma. The resulting processed samples were extracted with SPE and analyzed for TPD at limit of quantification (LOQ) 
level. The peak response of all the matrix components in the blank sample at TPD and IS retention times should be $<20$ and $5 \%$ of average peak response of TPD and TPD-d3 in LOQ level, respectively. Sensitivity of the method estimated by assessing the ratio between signal and noise $(\mathrm{S} / \mathrm{N})$ in 10 batches of screened and spiked LOQ-samples (Fahimirad et al., 2016; Rana et al., 2008; Titier et al., 2008). The $\mathrm{S} / \mathrm{N}$ was measured by the following formula:

$$
\frac{\mathrm{S}}{\mathrm{N}} \text { ratio }=\frac{\text { Signal }: \text { noise ratio of LOQ }}{\text { average signal: } \text { noise ratio of blanks }}>5
$$

\section{Precision and accuracy}

The inter- and intra-day precision and accuracy were processed for TPD in human plasma. Within a day, intra-run and between days inter-run accuracy was analyzed six replica samples of LOQ-QC, low, medium, and high quality control levels. Method precision was evaluated by determination of \% Relative standard deviation (RSD) for all quality control samples. The percentage deviation should be $<15.0$ (for LOQQC it should be $<20.0$ ). In the same way, the average accuracy should be $\pm 15 \%$ ( for LOQQC it should be $\pm 20 \%$ ) (Kirchherr and Kuhn, 2006).

\section{Linearity}

To prove the linearity of technique, three calibration curves were utilized. The peak area ratios of TPD were utilized to calculate regression coefficient. Least square $\left(1 / X^{2}\right)$ technique was utilized to determine the linearity curves individually. TPD concentrations were determined from each calibrator using back calculation technique. Regression coefficient finding should be $R^{2}>0.99$ desirable to all the linearity curves.

\section{Process efficiency}

TPD and TPD-d3 process efficiency (PE) at low, medium, and high quality control levels were estimated by observing the average peak area of TPD in six replica of extraction samples against the average peak area of TPD in un-extracted samples comprising TPD and TPD-d3 at concentration equals to those found in final TPD and TPD-d3 extraction samples. PE of TPD and TPD-d3 were measured by the following formula:

$\% \mathrm{PE}=\frac{\text { average peak area of analyte in extraction sample }}{\text { average peak area of analyte in un }- \text { extracted sample }} \times 100$

\section{Matrix effect}

It was estimated in the form of absolute matrix effect (AME) measured by the following formula:

$\%$ AME $=\frac{\text { average peak area of analyte in post extraction sample }}{\text { average peak area of analyte in un }- \text { extracted sample }} \times 100$

If AME value is one, it indicates that no interference of matrix components, less than one indicates ion suppression, and more than one indicates ion-enhancement (Titier et al., 2008).

\section{Dilution integrity}

It was processed by making the sample concentration nearly two times the $90 \%$ upper limit of quantification (ULOQ) concentration. The resultant solution was made dilution (two and four times) with blank plasma to get the solution concentration within the calibration range. Furthermore, the resulting samples were evaluated against fresh CS solution. The acceptance norms were same as precision and accuracy parameter.

\section{Reinjection reproducibility}

It was processed by reinjecting quality control samples from accepted precision and accuracy lot in the course of validation. The concentration of reinjected solutions was evaluated against the calibration standard solutions of the same precision accuracy lot, which were estimated 48 hours before. The percentage difference between re-injected and original values was measured by utilizing the formula:

$\%$ difference $=\frac{\mid \text { Original concentration }- \text { reinjected concentration } \mid}{\text { Original concentration }} \times 100$

\section{Stability}

Low and High quality control samples (6) were regained from the freezer after three freeze and thaw cycles. Samples were stored at $-30^{\circ} \mathrm{C}$ in three cycles of 24,48 , and 72 hours. For the long-term stability, QC samples were determined by analysis after 121 days of storage at $-50^{\circ} \mathrm{C}$. Bench-top stability was assessed for 6.5 hours period with standard concentrations. Stability solutions were prepared and extracted along with freshly spiked calibration standards. The accuracy and precision of the stability solutions should be $\pm 15 \%$ of their nominal concentrations. The auto-sampler stability estimated after 72 hours under auto-sampler (at $10^{\circ} \mathrm{C}$ ) condition. The freeze and thaw stability was performed by storing the $\mathrm{QC}$ samples at $-50^{\circ} \mathrm{C}$ (frozen) and thawed at room conditions for three times. The change in analyte concentration was less $(<15 \%)$ then the compound said to be stable (Kirchherr and Kuhn, 2006; Titier et al., 2008).

\section{Pharmacokinetics in healthy rabbits}

The kinetic constraints were measured by utilizing single dose by PK Solver from the results of plasma drug concentration verses time utilizing non-compartmental statistical method. The $C_{\max }$ and $T_{\max }$ were found directly from the concentration and time profiles. Linear trapezoidal technique was applied to estimate the

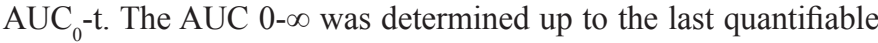
concentration and the terminal elimination-rate constant $(\mathrm{Ke})$. The Ke value was determined from the slope of the terminal exponential phase of the plasma of the linear regression method. The terminal elimination half-life $\left(t_{1 / 2}\right)$ was calculated from $0.693 / \mathrm{Ke}$.

\section{RESULTS AND DISCUSSION}

\section{Internal standard selection}

Identification and selection of IS was very important thing in an LC-MS/MS technique. The IS should have similar mass and chromatographic behavior with analyte to be determined. Stable isotope of particular analyte is the best and suitable IS for the technique. Therefore, TPD- $\mathrm{d}_{3}$ isotope chosen for TPD internal standard.

\section{Optimization mass conditions}

Negative mode Electro-spray ionization (ESI) technique was less effective when compared with positive ionization mode. Primarily, mass constraints were tried in ESI and API sources, but better results were obtained in APCI source. 


\section{Optimization of chromatography}

To get the better separation of TPD and TPD-d3, different kinds of phenyl and $\mathrm{C}_{18}$ stationary columns, such as Ascentis express, Hypurity-advance, Kinetex-ODS, Zorbax SB-ODS, Sunshell- $\mathrm{C}_{18}$, Luna-ODS(2), ACE-ODS PFP, and kinetex-PFP were tried. TPD and IS were well separated using Luna- $\mathrm{C}_{18} 100 \mathrm{~A}(5 \mu \mathrm{m}$, $100 \times 4.6 \mathrm{~mm}$ ) column. However, mobile phase ratio comprising buffer of ammonium acetate $(2 \mathrm{mM}) \mathrm{pH}-3.6$ and acetonitrile in the proportion of 10:90\% V/V was established optimal.

\section{Method validation}

Validation of the developed method was processed as per the regulatory guidelines and around was no nosiness detected at the retention time of TPD and TPD-d3 in the lots of plasma. The blank, blank with IS, LOQ, ULOQ and incurred sample chromatograms were represented in Figure 2. The S/N-ratio during the method validation was found to be more than 25 , which was acceptable in accordance with the guidelines of EMEA and USFDA.

The drug has LOQ value of $0.1210 \mathrm{ng} / \mathrm{ml}$ and the precision and accuracy values were found to be $8.62 \%$ and $98.12 \%$ at LOQQC concentration level. The linearity graph was linear over the concentration levels of $0.1210-35.6370 \mathrm{ng} / \mathrm{ml}$ for TPD. Linearity curve was made using peak response ratio of drug to IS and the " $R$ " value was estimated and the value was more than 0.99 . Precision and accuracy were processed and the findings were tabulated in Table 1. The inter day and intra-day precision were measured in \%RSD and the values were found between $1.730 \%$ and $11.380 \%$, and the inter- and intra-day accuracy findings were present between $97.34 \%$ and $103.74 \%$.

AME has an important role in ESI in mass system, which influences the ionization process of analyte by ion-suppression or

Table 1. Intra- and inter-day results.

\begin{tabular}{|c|c|c|c|c|}
\hline QC solutions & $\begin{array}{c}\% \text { intra-day } \\
\text { accuracy }^{1} \\
\left(\text { Mean } \pm \text { SDng/ }^{\prime}\right. \\
\text { ml) }\end{array}$ & $\begin{array}{c}\% \text { inter-day } \\
\text { accuracy } \\
\left(\begin{array}{c}\text { Mean }^{2} \pm \text { SDng/ }^{\prime} \\
\text { ml })\end{array}\right.\end{array}$ & $\begin{array}{c}\text { \%intra-day } \\
\text { precision }^{3}\end{array}$ & $\begin{array}{c}\text { \%inter-day } \\
\text { precision }\end{array}$ \\
\hline $\begin{array}{l}\text { LOQQC } \\
(0.122 \mathrm{ng} / \mathrm{ml})\end{array}$ & $\begin{array}{c}97.34 \\
(0.1188 \pm 0.009)\end{array}$ & $\begin{array}{c}98.12 \\
(0.119 \pm 0.0084)\end{array}$ & 11.38 & 8.62 \\
\hline $\begin{array}{l}\text { LQC } \\
(0.359 \mathrm{ng} / \mathrm{ml})\end{array}$ & $\begin{array}{c}103.74 \\
(0.372 \pm 0.036)\end{array}$ & $\begin{array}{c}102.24 \\
(0.367 \pm 0.04)\end{array}$ & 6.26 & 4.92 \\
\hline $\begin{array}{l}\text { MQC } \\
(14.358 \mathrm{ng} / \mathrm{ml})\end{array}$ & $\begin{array}{c}102.88 \\
(14.771 \pm 1.005)\end{array}$ & $\begin{array}{c}103.34 \\
(14.837 \pm 0.967)\end{array}$ & 2.29 & 1.91 \\
\hline $\begin{array}{l}\text { HQC } \\
(28.716 \mathrm{ng} / \mathrm{ml})\end{array}$ & $\begin{array}{c}102.94 \\
(29.56 \pm 2.17)\end{array}$ & $\begin{array}{c}103.50 \\
(29.721 \pm 1.892)\end{array}$ & 1.98 & 1.73 \\
\hline
\end{tabular}

${ }^{1} n=6$.

${ }^{2}$ Values found from three runs $(n=18)$.

${ }^{3} n=6$.
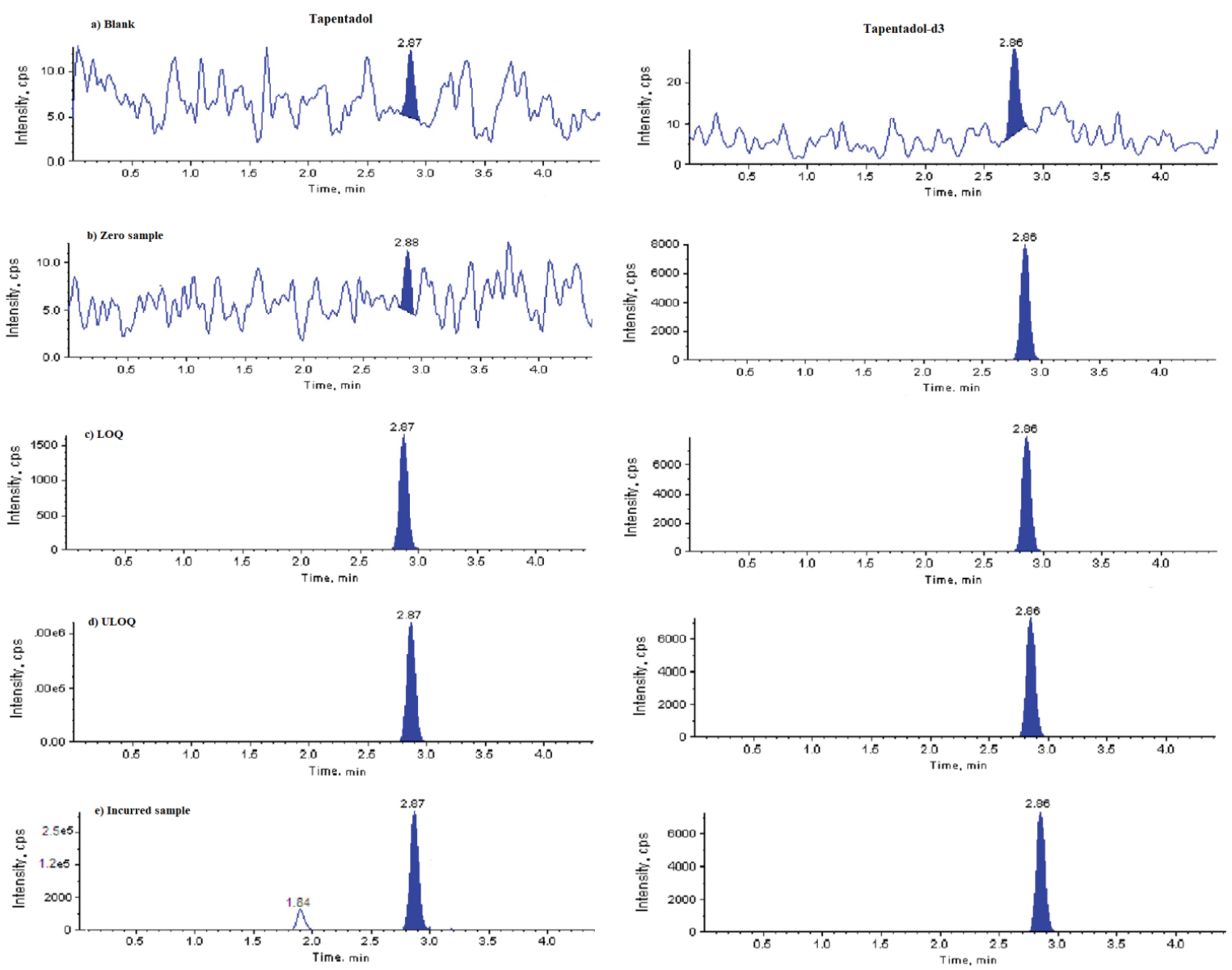

Figure 2. Representative chromatograms. (a) Blank, (b) TPD-d3, (c) Limit of quantification, (d) Upper LOQ, and (e) Incurred sample. 
enhancement. The AME was evaluated at quality control level and the $\%$ RSD values were found in the range of 0.84 to 4.50 . The findings shows that there was no effect of matrix components for analyte after the extraction of sample. The method PE for TPD and TPD-d3 were stable across all the quality control levels. An average process efficiency of TPD and IS were found to be $77.380 \%$ and $75.040 \%$, respectively. The $\%$ RSD of average process efficiency over low, medium, and high quality controls was less than 3 . The findings of $\mathrm{AME}$ and $\mathrm{PE}$ were represented in Table 2 and the relative matrix effect findings were tabulated in Table 3.

Stability studies of TPD were processed for Auto-sampler stability $\left(10^{\circ} \mathrm{C}, 76.90\right.$ hours), Bench top stability (ice-cold water, 6.5 hours), Freeze and thaw stability (3 freeze and thaw cycle),

Table 2. Tapentadol process efficiency and absolute matrix effect.

\begin{tabular}{|c|c|c|c|c|c|}
\hline $\begin{array}{l}\text { Quality } \\
\text { control } \\
\text { level }\end{array}$ & $\mathbf{A}^{1}\left(\% \mathrm{CV}^{2}\right)$ & $\mathrm{B}^{3}\left(\% \mathrm{CV}^{2}\right)$ & $\mathrm{C}^{4}\left(\% \mathrm{CV}^{2}\right)$ & $\% \mathrm{AME}^{5}$ & $\% \mathrm{PE}^{6}$ \\
\hline LQC & $39,590(3.6)$ & $38,498(4.3)$ & $26,841(4.1)$ & 98.81 & 75.87 \\
\hline MQC & $1,405,786(1.6)$ & $1,406,632(4.3)$ & $1,201,023(7.3)$ & 99.35 & 79.91 \\
\hline $\mathrm{HQC}$ & $2,812,201(0.9)$ & $2,701,598(0.8)$ & $2,109,915(1.8)$ & 97.26 & 76.54 \\
\hline
\end{tabular}

${ }^{1}$ Average peak area of 6 replicates processed in re-constitution solution.

${ }^{2}$ Coefficient of variation.

${ }^{3}$ Average peak response of 6 replicates processed by spiking blank sample.

${ }^{4}$ Average peak area of 6 replicates processed by spiking pre-extraction.

${ }^{5} \mathrm{~B} / \mathrm{A} \times 100$.

${ }^{6} \mathrm{C} / \mathrm{A} \times 100$.

Table 3. Tapentadol matrix effect.

\begin{tabular}{|c|c|c|c|c|}
\hline \multirow[b]{2}{*}{ Plasma batch } & \multicolumn{2}{|c|}{ LOQQC (0.122 ng/ml) } & \multicolumn{2}{|c|}{ HQC (28.716 ng/ml) } \\
\hline & $\begin{array}{c}\text { Average } \\
\text { concentration } \\
\left(\% \mathrm{CV}^{1}\right)\end{array}$ & $\%$ bias & $\begin{array}{c}\text { Average } \\
\text { concentration } \\
\left(\% \mathrm{CV}^{1}\right)\end{array}$ & $\%$ bias \\
\hline 1 & $0.121(1.2)$ & -0.82 & $28.799(0.20)$ & 0.29 \\
\hline 2 & $0.122(5.2)$ & 0 & $28.632(0.00)$ & -0.29 \\
\hline 3 & $0.126(4.5)$ & 3.28 & $28.145(1.80)$ & -1.99 \\
\hline 4 & $0.118(0.6)$ & -6.56 & $29.527(0.70)$ & 1.14 \\
\hline 5 & $0.114(4.4)$ & -3.28 & $29.042(0.80)$ & 2.82 \\
\hline 6 & $0.121(4.1)$ & -0.82 & $28.960(0.40)$ & 0.85 \\
\hline
\end{tabular}

${ }^{1}$ Coefficient of variation.
Long term stability $\left(-50^{\circ} \mathrm{C}, 121\right.$ days $)$ and all the findings were shown in Table 4. The detected average nominal concentrations of TPD were within $\pm 15 \%$ of their particular nominal concentration. There was no change in the concentration of TPD drug in human$\mathrm{K}_{3}$ EDTA for 2.0 hours.

Method Reinjection reproducibility was proven by reinjecting quality control solutions of precision and accuracy lot-3 and quantified against the actual estimated linear graph of precision and accuracy lot 3 . The $\%$ change for all the reinjected quality control solutions were $\leq 7.450$.

\section{Application of pharmacokinetic study}

Developed and validated technique was utilized in the estimation of TPD in human plasma samples to study the kinetics of single oral dose of $300 \mu \mathrm{g} / 1.8 \mathrm{~kg}$ body weight (equivalent to $4 \mathrm{mg}$ capsule) in six healthy rabbits. Graph was plotted by taking plasma concentration of TPD on $Y$-axis and time on $X$-axis, the results were represented in Figure 3. This plot was plotted by considering the data between 0 and 12 hours. TPD shown $T_{\max }$ of $2.27 \pm 0.025$ and mean $C_{\max }, \mathrm{AUC}_{0 ® \mathrm{t}}$ and $\mathrm{AUC}_{0 \circledast \mathrm{a}}$ for Test formulation is $294.82 \pm 38.02,852.72 \pm 151.14$, and $960.45 \pm 205.069$, respectively. The findings were shown in Tables 5 and 6.

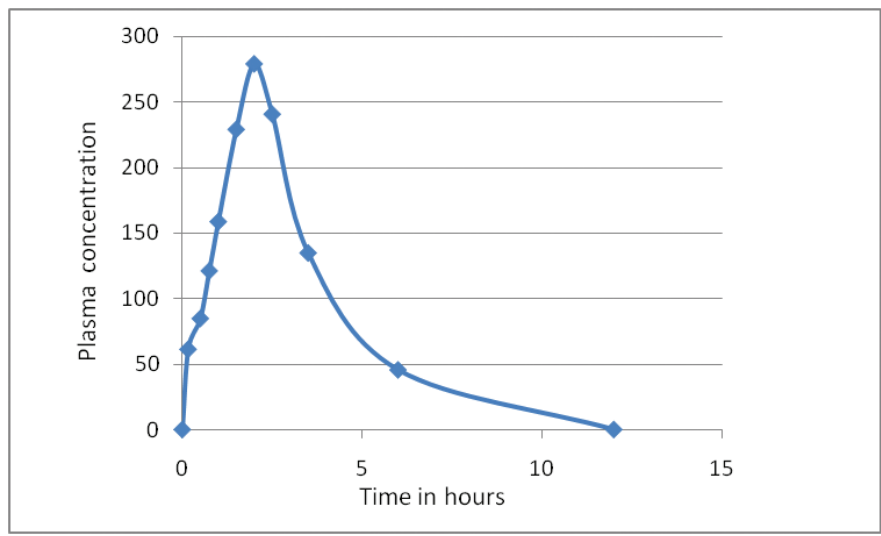

Figure 3. Plasma (mean) concentration of TPD—time profile curve.

Table 4. Tapentadol stability.

\begin{tabular}{|c|c|c|c|c|c|c|}
\hline Stability type & $\begin{array}{c}\text { Concentration } \\
\text { level }\end{array}$ & $\begin{array}{c}\text { Comparison sample } \\
(\mathrm{ng} / \mathrm{ml})\end{array}$ & $\% \mathrm{CV}$ & $\begin{array}{l}\text { Stability sample } \\
\text { concentration }\end{array}$ & $\% \mathrm{CV}$ & $\%$ Change \\
\hline \multirow{3}{*}{ Bench top stability (ice-cold water for 6.5 hours) } & LQC & 0.358 & 1.46 & 0.359 & 2.6 & 2.64 \\
\hline & HQC & 28.832 & 1.82 & 28.716 & 1.85 & -0.57 \\
\hline & LQC & 0.358 & 7 & 0.359 & 1.57 & -1.95 \\
\hline \multirow[t]{2}{*}{ Auto-sampler stability $\left(10^{\circ} \mathrm{C}\right.$ for 76.90 hours $)$} & HQC & 28.832 & 1.27 & 28.716 & 1.38 & 1.35 \\
\hline & LQC & 0.358 & 2.35 & 0.359 & 2.43 & 0 \\
\hline Long-term stability $\left(-50^{\circ} \mathrm{C}\right.$ for 121 days) & HQC & 28.832 & 0.63 & 28.716 & 0.96 & 3.94 \\
\hline \multirow{2}{*}{ Freeze/thaw stability } & LQC & 0.358 & 1.46 & 0.359 & 2.75 & 2.05 \\
\hline & HQC & 28.832 & 1.82 & 28.716 & 1.85 & 0.36 \\
\hline
\end{tabular}

CV: Coefficient of variation. 
Table 5. Estimated plasma concentrations of healthy rabbits.

\begin{tabular}{|c|c|c|c|c|c|c|c|c|}
\hline \multicolumn{9}{|c|}{ Estimated concentrations in $\mathrm{ng} / \mathrm{ml}$} \\
\hline Time (hours) & Rabbit-1 & Rabbit-2 & Rabbit-3 & Rabbit-4 & Rabbit-5 & Rabbit-6 & Mean & SD \\
\hline 0 & 0 & 0 & 0 & 0 & 0 & 0 & 0 & 0 \\
\hline 0.16 & 48 & 64 & 71 & 33 & 65 & 86 & 61.17 & 18.45 \\
\hline 0.5 & 67 & 89 & 98 & 59 & 84 & 111 & 84.67 & 19.29 \\
\hline 0.75 & 95 & 122 & 144 & 109 & 112 & 144 & 121.00 & 19.80 \\
\hline 1 & 138 & 165 & 183 & 123 & 155 & 187 & 158.50 & 25.09 \\
\hline 1.5 & 227 & 234 & 251 & 161 & 244 & 256 & 228.83 & 34.90 \\
\hline 2 & 284 & 277 & 298 & 214 & 301 & 299 & 278.83 & 33.16 \\
\hline 2.5 & 168 & 321 & 198 & 228 & 185 & 343 & 240.50 & 73.87 \\
\hline 3.5 & 106 & 146 & 154 & 111 & 123 & 168 & 134.67 & 25.03 \\
\hline 6 & 29 & 48 & 62 & 18 & 46 & 70 & 45.50 & 19.53 \\
\hline 12 & 0 & 0 & 0 & 0 & 0 & 0 & 0 & 0 \\
\hline
\end{tabular}

$\mathrm{SD}=$ Standard deviation

Table 6. Test animals estimated average values of PK parameters.

\begin{tabular}{cccc}
\hline Parameter & Unit & $\begin{array}{c}\text { Mean value } \\
(\boldsymbol{n}=\mathbf{6})\end{array}$ & SD \\
\hline Lambda_z & $1 / \mathrm{h}$ & 0.48731 & 0.13558 \\
$t_{1 / 2}$ & $\mathrm{H}$ & 1.50741 & 0.37908 \\
$T_{\max }$ & $\mathrm{H}$ & 2.27 & 0.27386 \\
$C_{\max }$ & $\mathrm{ng} / \mathrm{ml}$ & 294.822 & 38.02 \\
$T_{\text {lag }}$ & $\mathrm{H}$ & 0 & 0 \\
$C_{\text {last_obs }} / C_{\max }$ & & 0.14926 & 0.05223 \\
AUC 0-t & $\mathrm{ng} / \mathrm{ml}{ }^{* h}$ & 852.72 & 151.14 \\
AUC 0-inf_obs & $\mathrm{ng} / \mathrm{ml} * \mathrm{~h}$ & 960.45 & 205.069 \\
AUC 0-t/0-inf_obs & & 0.89669 & 0.04644 \\
AUMC 0-inf_obs & $\mathrm{ng} / \mathrm{ml} * \mathrm{~h}^{\wedge} 2$ & 3053.83 & 936.775 \\
MRT 0-inf_obs & $\mathrm{H}$ & 3.11926 & 0.36743 \\
Vz/F_obs & $(\mathrm{mg}) /(\mathrm{ng} / \mathrm{ml})$ & 0.00296 & 0.00055 \\
Cl/F_obs & $(\mathrm{mg}) /(\mathrm{ng} / \mathrm{ml}) / \mathrm{h}$ & 0.00141 & 0.00031 \\
\hline
\end{tabular}

\section{CONCLUSION}

A rapid, specific, accurate, and sensitive LC-MS/MS technique was developed and validated to analyze tapentadol using tapentadol- $\mathrm{d}_{3}$ as IS in human plasma. This validated LC$\mathrm{MS} / \mathrm{MS}$ technique can be useful in high throughput analysis and has been effectively applied to study the pharmacokinetics of tapentadol in rabbits. The intra-day precision and inter-day precision in \% RSD ranged from $1.73 \%$ to $11.38 \%$ and the intraday and inter-day accuracy ranged from $97.34 \%$ to $103.74 \%$. The average process efficiency of TPD and TPD-d 3 by this technique were $77.38 \%$ and $75.04 \%$, respectively. LOQ was $0.121 \mathrm{ng} /$ $\mathrm{ml}$ of TPD in plasma. The precision and accuracy at LOQQC concentration were $8.620 \%$ and $98.120 \%$, respectively. The pharmacokinetic studies of tapentadol have shown $T_{\max }$ of 2.27 \pm 0.025 and mean $C_{\max }, \mathrm{AUC}_{0 \circledast \mathrm{t}}$ and $\mathrm{AUC}_{0 \circledast \mathrm{a}}$ for Test formulation is $294.82 \pm 38.02,852.72 \pm 151.14$, and $960.45 \pm 205.069$, respectively.

\section{CONFLICTS OF INTEREST}

The authors declare that there are no conflicts of interest.

\section{REFERENCES}

Badenhorst D, Sutherland FCW, De Jager AD. Determination of doxepin and desmethyldoxepin in human plasma using liquid chromatography-tandem mass spectrometry. J Chromatogr B, 2000; 742:91-8.

Chen YA, Hsu KY. Development of a LC-MS/MS-based method for determining metolazone concentrations in human plasma: application to a pharmacokinetic study. J Food Drug Anal, 2013; 21:154-9.

Coulter C, Taruc M, Tuyay J, Moore C. Determination of tapentadol and its metabolite n-desmethyltapentadol in urine and oral fluid using liquid chromatography with tandem mass spectral detection. J Anal Toxicol, 2010;34:458-63.

Fahimirad B, Asghari A, Bazregar M. Application of tandem dispersive liquid-liquid microextraction for the determination of doxepin, citalopram, and fluvoxamine in complicated samples. J Sep Sci, 2016; 39:4828-34.

Fidman B, Nogid A. Role of tapentadol immediate release (Nucynta)in the management of moderate-to-severe pain. Pharm Ther, 2010; 35(6):330-57.

Gaurang P, Hitendra S Joshi. Development and validation of stability indicating HPLC assay method for determination of tapentadol in tablet formulation. Int J Sci Eng Res, 2013; 4(4):1288-92.

Haritos H, Ghabrial JT Ahokas. Stereoselective measurement of Eand Z-doxepin and its N-desmethyl and hydroxylated metabolites by gas chromatography-mass spectrometry. J Chromatogr B, 1999; 736:201-8.

Jaivik V, Shaha Priyanka A, Shaha Priya V, Shahb Mallika, Sanyalc Pranav S, Shrivastav. Fast and sensitive LC-MS/MS method for the simultaneous determination of lisinopril and hydrochlorothiazide in human plasma. J Pharm Anal, 2017; 7:163-9.

Kirchherr H, Kuhn-Velten WN. Quantitative determination of forty-eight antidepressants and antipsychotics in human serum by HPLC tandem mass spectrometry: a multi-level, single-sample approach. J Chromatogr B, 2006; 843:100-13.

Leonhart MM. Schedules of controlled substances: placement of tapentadol into schedule II. Fed Reg, 2009; 74(97):23790-93.

Mahaparale S, Samuel N. Quantitative estimation of tapentadol hydrochloride in human plasma by HPLC. Pharmacophore, 2015; 6(5):24954.

Nossaman VE, Ramadhyani U, Kadowitz PJ, Nossaman BD. Advances in perioperative pain management: use of medications with dual analgesic mechanisms, tramadol \& tapentadol. Anesthesiol Clin, 2010; 28(4):647-66.

Patel NP, Sanyal M, Sharma N, Patel DS, Shrivastav PS, Patel BN. Highly sensitive LC-MS/MS method to estimate doxepin and its 
metabolite nordoxepin in human plasma for a bioequivalence study highly sensitive LC-MS/MS method to estimate doxepin and its metabolite nordoxepin in human plasma for a bioequivalence study. J Pharm Anal, $2017 ; 6: 145-50$.

Raffa RB, Buschmann H, Christoph T, Eichenbaum G, Englberger W, Flores CM, Hertrampf T, Kögel B, Schiene K, Straßburger W, Terlinden R, Tzschentke TM. Mechanistic and functional differentiation of tapentadol and tramadol. Expert Opin Pharmacother, 2012; 13(10):143749.

Rana S, Uralets VP, Ross W. A new method for simultaneous determination of cyclic antidepressants and their metabolites in urine using enzymatic hydrolysis and fast GC-MS. J Anal Toxicol, 2008; 32:355-63.

Singh DR, Nag K, Shetti AN, Krishnaveni N. Tapentadol hydrochloride: a novel analgesic. Saudi J Anaesth, 2013; 7(3):322-6.

Titier K, Castaing N, Le-Deodic M. Quantification of tricyclic antidepressants and monoamine oxidase inhibitors by high-performance liquid chromatography-tandem mass spectrometry in whole blood. J Anal Toxicol, 1997; 21:200-7.
Tzschentke TM, et al. Tapentadol hydrochloride. DrugsFuture, 2006; 31(12):1053

WHO. Tapentadol: expert peer review on pre-review report (PDF). World Health Organization, Geneva, Switzerland, Retrieved 16 March 2014.

\section{How to cite this article:}

Adluri P, Kumar YS. Development and validation of stability indicating LC-MS/MS Technique for the quantification of tapentadol in biological matrices: Application to bioavailability study in healthy rabbits. J Appl Pharm Sci, 2019; 9(10):068-074. 